\title{
Diets and the Heart. So Many to Choose from, but Which Work?
}

\author{
Lionel Opie
}

Published online: 3 December 2014

(C) Springer Science+Business Media New York 2014

The importance of diet for cardiovascular protection as related to life-style has already been evaluated [1]. Yet the choice of diet is often perplexing. Diets such as those chosen to lose weight need to be disguised from dietary patterns of eating. There are only two evidence based dietary patterns of eating, namely the Mediterranean and the new Atkins diet $[2,3]$. These were both evaluated in a 2 year Israeli study with the conclusion that each had a contribution, the Mediterranean diet for improving mortality when tested over 5 years, and the New Atkins diet for improving weight loss when tested over 2 years $[2,3]$. Of these, the Mediterranean dietary pattern has in its favour improved mortality over 5 years, whereas both the Mediterranean pattern and the New Atkins diet when assessed over 2 years.

However, these diets work by different mechanisms, the Mediterranean pattern working through high intakes of nuts and/or olive oil, with the New Atkins diet working through weight reduction. In sharp contrast, regarding popular mens' health journals, the dietary content, format and scientific basis all leave much to be desired [4]. The basic issue in weight loss remains calorie restriction [5] as already emphasised in 1969 [6]. Weight-loss maintenance after initial weight loss remains a major challenge in obesity treatment. [7]. Anti-obesity drugs, meal replacements, and high-protein diets were all associated with improved weight-loss maintenance after a very low or low calorie diet, whereas there was no effect of dietary supplements nor exercise [7]. Running exercise may not improve weight loss, but even 5 to $10 \mathrm{~min} /$ day and at slow speeds $<6$ miles/h reduced risks of death from all causes and cardiovascular disease [8]. Thus, after all, the combination of diet and exercise remains the best choice that physicians can advocate to their patients.

\section{References}

1. Life-style, drugs and diet for cardiovascular protection. Cardiovasc. Drugs. Ther. Submitted, 2014.

2. Esposito K, Giugliano D. N Engl J Med. 2013;369:674-5.

3. Shai I, Schwarzfuchs D, Henkin Y, et al. Dietary intervention randomized controlled trial (DIRECT) group. Weight loss with a low-carbohydrate, Mediterranean, or low-fat diet. N Engl J Med. 2008;359:229 41.

4. Cook TM, Russell JM. Barker ME dietary advice for muscularity, leanness and weight control in Men's health magazine: a content analysis. BMC Public Health. 2014; 14:1062.

5. Su HY, Lee HC, Cheng WY, Huang SY. A calorie-restriction diet supplemented with fish oil and high-protein powder is associated with reduced severity of metabolic syndrome in obese women. Eur J Clin Nutr. 2014 Sep 24

6. Oscai LB, Holloszy JO. Effects of weight changes produced by exercise, food restriction, or overeating on body composition. J Clin Invest. 1969;48:2124-8.

7. Johansson K, Neovius M, Hemmingsson E. Effects of anti-obesity drugs, diet, and exercise on weight-loss maintenance after a very-lowcalorie diet or low-calorie diet: a systematic review and meta-analysis of randomized controlled trials. Am J Clin Nutr. 2014;99:14-23.

8. Lee DC, Pate RR, Lavie CJ, et al. Leisure-time running reduces allcause and cardiovascular mortality risk. J Am Coll Cardiol. 2014;64: $472-81$.
L. Opie $(\bowtie)$

Hatter Institute for Cardiovascular Research in Africa, University of Cape Town Medical School, Observatory, Cape Town 7625, South Africa

e-mail: lionel.opie@uct.ac.za 